\title{
Enquiry-Based Learning Online: Course Development and Student Experience of a First-Year Enquiry-Based Learning Seminar
}

\author{
Jacqueline Murray, University of Guelph \\ Nathan John Lachowsky, University of Victoria \\ Natalie Green, University of Guelph
}

DOI: $10.22329 /$ celt.v10i0.4744

Online courses are increasing in popularity while universities are using first-year seminars to address the challenges of large impersonal classes, lack of student engagement, and increased skills development. Could the learning experience and benefits of an in-person first-year seminar be achieved through an online distance education (DE) format? How would students' experience benefit from an online DE first-year seminar? At the University of Guelph, an online interdisciplinary first-year seminar was developed and offered four times. This essay includes reflections from the faculty instructor and educational developer who co-designed the course, results from pre-and post-course surveys completed by students, and interviews conducted with students.

\begin{abstract}
$\Delta$ cross North America and beyond, universities are Aimplementing various innovations to enhance student engagement and student learning. Various programs and pedagogies have been identified as high-impact educational practices, including firstyear seminars, learning communities, collaboration, research, and experiential learning, among others (Kuh, 2008). One high-impact pedagogy that is particularly well suited to meet these learning goals and to foster student engagement is closed-loop reiterative enquiry-based learning (EBL). This pedagogy was originally articulated in medical education by Barrows (1986), who analyzed variations of problem-based learning to identify which best addressed students' learning. In particular, Barrows wanted a pedagogy that would achieve learning goals such as structuring knowledge, problem-solving, self-directed learning, and enhanced motivation for learning, goals that were
\end{abstract}

met by closed-loop reiterative problem-based learning. In order to avoid confusion with other pedagogies that in some way incorporate the use of problems or cases, Summerlee \& Murray (2010) proposed further clarification, suggesting this specific pedagogy would be better termed closed-loop reiterative enquiry-based learning.

At the University of Guelph, EBL pedagogy has been used in various courses and topics, particularly in interdisciplinary first-year seminars, and has demonstrated significant results for student learning (Murray \& Summerlee, 2007; Summerlee \& Murray, 2010). The current study examines the process of developing and offering a first-year, enquiry-based seminar online. The experience of the instructor, instructional designer, and one of the students has been discussed previously (Murray, Giesbrecht, \& Mosonyi, 2013). Here we will reflect upon the course development and report on the 
research, over four cohorts of students (62 completed the course), to assess student engagement and learning outcomes. Thus, it will be possible to reflect upon the relative merits of EBL and online applications of EBL.

\section{Closed-Loop Reiterative Enquiry-Based Learning}

Closed-loop reiterative enquiry-based learning is rooted in constructivist learning theory and problembased learning methods (Barrows, 1986; HmeloSilver, 2004; Kemp, 2011; Savery \& Duffy, 2001). It is designed for students to develop skills and gain an integrated and sophisticated approach to understanding complex issues (Duch, Allen, \& White, 1998; Murray \& Summerlee, 2007). Enquiry places the emphasis of the learning process on investigation rather than finding information or answers. This reinforces the pedagogical intention to be process focused rather than content focused. Of critical significance, EBL slows the thinking process so students experience deep learning and deep understanding of the issues they are studying.

Enquiry-based learning is a student-driven pedagogy that provides learners with the opportunity to examine real-world, authentic problems, and engage in research and co-investigation to create knowledge. Students examine scenarios which are deliberately complex, even internally contradictory, contain limited information, and require further explanation and exploration. This creates the cognitive dissonance necessary for deep learning (Weimer, 2014). Scenarios cannot be understood upon superficial reading but need careful analysis through the three fundamental EBL steps. Students ask "What do we know?" and when everything is identified they move on to their burning question, "What don't we know?" It is important that the facilitator(s) do not provide answers to these questions so that students are empowered to take control of their own learning rather than relying on the teacher to provide answers. In the final step, students identify "What we need to find out," the learning issues they need to research. Each member of the group takes a learning issue to research individually and then presents the relevant and important information to help illuminate the problem and adds to the group's understanding of the scenario. Research is presented to the group which then analyzes the scenario in light of this new information. At this point, the case may be explicated, or new learning issues may emerge, in which case the process begins anew. At every step, the group engages in group processing, in which each student and facilitator provide one piece of constructive feedback on recent contributions for every group member and themselves. This can take significant time, but, given the importance of group processing to student learning and the subordinate role of content over process, it is well worth it. Students receive continuous feedback and learn to give and receive constructive criticism without defensiveness. This process allows students to develop a realistic understanding of their own strengths and areas for improvement. In EBL, the cognitive load of working through complex problems is distributed among group members and, as research is conducted and discussion unfolds, members benefit from the group's collective expertise (Hmelo-Silver \& DeSimone, 2013). Moreover, through its various steps and processes, EBL addresses Chickering and Gamson's (1987) criteria for good practice in undergraduate education, as well as Fink's (2003) articulation of significant learning.

\section{Enquiry-Based Learning Online}

There are various examples of courses using problembased learning (broadly defined) online, many of which report mixed reviews. Some courses introduced pedagogical flexibility or innovations to the process, or omitted or modified crucial steps, for example, in response to student discomfort with an unfamiliar pedagogy (Donnelly, 2004). Others struggled with the challenges of developing true online learning communities and collaborative rather than individual learning (Kear, 2010). Even courses that were deeply committed to the principles of closed-loop reiterative problem-based learning, as articulated by Barrows 
(1986), and which were considered highly successful, nevertheless, omitted group processing in favour of generalized discussion (Kenny, 2006).

One of the central pedagogical features of EBL is that it is characterized by small groups that engage in regular, intense interaction at every stage of the process (except individual research). This intensity accounts for the significant social and academic outcomes, in terms of student engagement and learning (Summerlee \& Murray, 2010). The challenge in developing the online course was how to capture the interactivity, collaboration, and learning experienced in classroom-based EBL courses. Our goal was to ensure that students could flourish in their individual learning communities and exercise their collective autonomy while being faithful to an unfamiliar medium, an unfamiliar pedagogy, and an unfamiliar degree of self-direction. These were some of the questions that underscored the development of the online seminar, UNIV*1150 "The Politics, Science, and Culture of Hunger."

A number of classroom-based examples of EBL seminars provided the background and foundation to develop the online seminar. The instructor was experienced and had facilitated many EBL seminars at the first-year level, and this online course was similarly offered exclusively to first-year students. One particular benefit of the instructor working closely with the instructional designer was the ability to outline not only what happens at each stage of learning, but also what was the intent, and what the various responses from students might be.

Online EBL requires a different pedagogical approach than most online courses because the learning is driven by a process of enquiry and the students decide what, when, and how they learn (Savin-Badin, 2007). The pedagogy is processoriented rather than content-oriented. Consequently, the course design centred on process-related supports and tools to foster student-facilitator, studentstudent, and student-content interactions, rather than the typical content-based, modularized approach to online courses (Anderson, 2008).

It was important to balance the pedagogical imperatives and learning outcomes of closed-loop reiterative EBL, as facilitated in-class, with the unique differences and affordances of an online learning environment. Similar to any in-class to online course conversion, adapting EBL online required redefining the learning design rather than repackaging in-class practices and posting them into a learning management system. Consequently, moving EBL online required considerable planning before implementation. As part of good instructional design practice, the design needed to look at the learning goals and outcomes, the assessment, and how these constructively aligned (Blumberg, 2009). Further, the success of EBL online necessitated a course framework that supported the enquiry process as well as the social dimension of learning (Kahn \& O'Rourke, 2004). As a result, the course design for UNIV $^{*} 1150$ structured the stages of enquiry and collaboration through pedagogical supports and online technologies.

In an in-class EBL course, interactions are time-based and generally occur within the constraints of the institution's course scheduling. However, $\mathrm{UNIV}^{*} 1150$ was conducted in an asynchronous online environment. Consequently, the course design was structured to provide group members with continual opportunities for interaction. Students were able to contribute research and post messages to their group at any time that was personally convenient. The facilitator was able to check on individual and collective progress to ensure the group worked in a timely manner. Group interactions evolved continuously, over a few days, which afforded students flexibility and autonomy in their selfdirected learning. This also provided students with time to reflect on their own contributions and those of their peers, and to engage in deeper conversations, as well as to exercise individual self-governance, something that has been linked to success in online collaborative learning communities (Kenny, 2006; Lin \& Vassar, 2009).

Like all enquiry-based learning courses, EBL online was not content-based, thus, clear student expectations needed to be made explicit from the outset. The learning environment was organized into sections that outlined the course syllabus, evaluation criteria, schedule, and course information, expectations, and a variety of supports around EBL and course technologies. The section about EBL outlined the learning process, providing students with 
written instructions that were supplemented by a multimedia object that provided a step-by-step guide through the EBL process. A video of students working through an in-class EBL scenario provided a model to help online learners visualize the process (Kahn \& O'Rourke, 2004). To foster successful collaboration and shared understanding, learning groups were also provided with materials that discussed working in groups, setting ground rules, and creating action plans (Goldring \& Wood, 2009).

The primary mode of assessment in the course focused on the analysis of the cases. These helped the students develop competency in areas such as identifying and analyzing complex questions and critically evaluating information from multiple sources. Students were assessed on the quality and regularity of their participation, the quality of their analysis and research contributions, and the effectiveness of their presentations. As with in-class EBL, this assessment was based on peer and selfevaluation in the form of regular group processing. This was formalized at mid-semester and the end of the semester by lengthier written assessments using rubrics. Students had two opportunities for formal written assignments, which were graded by the facilitator. First, at mid-semester, students critically reflected on issues raised in the course and how their personal understanding of world hunger had evolved. Second, at the end of the semester, students individually analyzed a final case assignment that allowed them to deploy the skills they had developed over the course.

\section{Technologies to Support EBL Online}

The focus of all quality online course designs is the student learning experience. Therefore, it is essential to select technology that is appropriate to the specific pedagogical approach and learning outcomes. Additionally, because EBL demands high levels of student interaction and collaboration, it requires technology that facilitates the learning process clearly and simply.
Online courses at the University of Guelph are facilitated through the Desire2Learn Brightspace learning management system. Within this environment, a course website served as an interactive hub to connect students through discussion forums and to link them to external tools that supported the enquiry-based analysis and research process. Because the course required high levels of interaction and collaborative writing, the SECTIONS model (Bates, 2015; Bates \& Poole, 2003) was used to assess which tools would ensure students' ability to share and edit ideas quickly while promoting the development of a learning community (Palloff \& Pratt, 2005).

\section{Wikis: Brainstorming and Presentations}

In the classroom, EBL relies on educational technologies such as chart paper or a whiteboard, which learning groups use to visualize and guide their thought processes (Hmelo-Silver, 2004). In UNIV $^{*} 1150$, a wiki was integrated to support active brainstorming and collaboration. Wikis facilitate the production of collaborative texts and let group members add content and edit what has already been published, without requiring all members to be online simultaneously. Collaboration in EBL often requires prompt feedback, so a wiki allows concurrent editing and the tracking of individual contributions, while still operating in the context of an asynchronous course.

Each learning group had its own private wiki site to ensure groups had the flexibility to evolve the environment as they wished, without outside observers. The framework for the wiki supported pivotal points in the collaboration process and helped to encourage group members to be actively involved (Hmelo-Silver, 2004).

For each case, the navigation consisted of individual web pages for analysis, research, and presentation, pre-populated with headings and guidance. This structure provided groups with scaffolding to promote self-directed learning, as well as a starting point until they were able to self-organize 
and acquire confidence in constructing and modifying their contributions (Vygostky, 1978; West \& West, 2009).

As students worked through the cases, the processes used to understand the scenarios were frequently the key learning outcome. For other cases, the outputs were more concrete such as a project proposal to an organization. In both types of cases, the artefacts illustrated how individual contributions and collaborative synthesis worked together. These were archived so that students could iteratively engage in reflection and peer and self-assessment.

Collaborative work on the wiki site aimed not only to help students develop research, writing, and editing skills, but also skills in information and digital literacy. Because the environment was open to all group members, each student's contributions were subject to scrutiny, constructive criticism, and peer editing. This can be a challenging experience for students, however, they learned to negotiate control over this shared workspace and to build trust and mutual confidence that the outcomes of their collective contributions would result in a deeper level of learning and a stronger final product (Gokhale, 1995; West \& West, 2009)

\section{Discussion Forums: Community Building and Interactivity}

Discussion forums served to accommodate normal course communication and allowed learning groups a private place in which to present and elaborate on ideas asynchronously. Discussion forums were used in a variety of ways, from those designed to foster social interaction to those focussed on the EBL process and case analysis.

The development of a learning community is indispensable to the EBL pedagogy. A learning community can be defined as a community that "consists of learners who support and assist each other, make decisions synergistically, and communicate with peers on topics beyond those assigned" (Boettcher \& Conrad, 2004, p. 120). Through their interactions, members of the community construct knowledge as they internalize what they are learning from each other (Vygotsky, 1978). In online EBL, the transformation of groups into true learning communities encourages the development of knowledge, competencies, and mutual respect.

A successful collaborative environment is contingent upon the creation of a learning community and therefore community-building opportunities were integrated into the course from the start (Palloff \& Pratt, 2005). In UNIV*1150, an introductory activity framed by guiding questions provided each learning group with an opportunity for social interaction. Additional forums encouraged students to share interesting information and resources with their peers and to connect socially on topics beyond the purview of the course. This process was also intended to reduce social isolation, impersonality, and social loafing by facilitating interaction between group members and enhancing their online social engagement (Kear, 2010; Swan, 2002). Through open discussion, students develop confidence in communicating online and with navigating the online environment. The goal was to develop a strong sense of community within each learning group, not only to develop the group but also each individual member (Palloff \& Pratt, 2005).

A considerable amount of discussion and collaboration occurred in the case discussion forums. Forums were structured to model the EBL process and the stages of collaboration. A learning group would request the facilitator to open a discussion forum dedicated to the scenario. As groups engaged in various stages of the case, they accessed forums that contained exhibits or resources or further information, which they discussed in-depth and integrated with their research posted on the wiki. They also used forums to conduct group processing. Discussions supported the consolidation of learning during the analysis of a scenario and at the end of a case and provided groups with the opportunity to reflect on what they had learned and how effectively they had collaborated. These discussions promoted the transfer of learning to subsequent cases (HmeloSilver, 2004). 


\section{Peer and Self-Assessment}

Regular group processing is crucial to the success of EBL. It provides students with practice in giving and receiving constructive feedback fairly and without defensiveness. Students come to a deeper understanding of their own strengths and areas for improvement and how they function as a member of a team. Regular group processing in the forums prepared students for the more in-depth and formal written peer- and self-assessment exercises. The Peer Evaluation, Assessment and Review (PEAR) tool, developed at the University of Guelph, was selected to support this process. Using a Likert-scale and open-ended questions, organized under four rubrics reflecting different areas of activity and skill development, students reflected on their own participation and that of each member of the learning group, including the facilitator. The open-ended questions required students to address the strengths and areas of improvement under each rubric, avoiding formulaic compliments. The assessments were not anonymous, which ensured mutual accountability and ultimately reinforced trust among group members. Once the assessment period ended, students could access their assessments to reflect upon their performance and address the areas suggested for improvement.

Having developed an online course design that suited the pedagogy, it was imperative that we engage in research into the outcomes of this experiment.

\section{Research Methods}

This study used a mixed method approach, combining quantitative and qualitative methods, to assess student experience and outcomes. Participants were first-year students enrolled in the course in one of four offerings (2011-2014); we invited all students to complete quantitative questionnaires anonymously, online, at the beginning and end of the semester. At the end of the semester, we invited participants to complete a qualitative semi-structured individual interview or participate in a focus group.
The second author, who had no connection to or instructional responsibilities for the course, recruited the participants and conducted the interviews and focus groups. The focus groups were mixed across instructional sections. Written informed consent was secured from each participant prior to both the quantitative and qualitative portions of the study. We did not provide honoraria or reimbursement for participation. The University of Guelph Research Ethics Board approved the study protocol (REB\#11MR017).

Three quantitative questionnaires asked students to reflect upon their experiences with technology, learning skills, and research resource use. In the first year the course was offered, only the research resources questionnaire was administered because ethics approval was still pending for the other two questionnaires. The questionnaires took approximately 15 minutes to complete and were a mix of closed-option yes/no and Likert-type scale questions. The data were collected electronically, imported into Stata/SE 13.1 software, and coded for the time of the survey (pre/post, indicating the beginning and end of the semester) and year (2011, 2012, 2013, and 2014). Descriptive statistics were prepared as counts $(n)$ and proportions (\%) or means (for Likert-scale questions). We used multilevel mixed-effects linear regression, with instructional year included as a grouping variable, to account for the fact that students completed both pre- and postcourse surveys within the same year $(p<0.05$ was considered a statistically significant difference).

The qualitative individual interviews and focus groups were conducted in a small room on campus using the same semi-structured question guide, which asked students to reflect upon the experiences in the course, how it differed from other courses, what and how they learned, the grouplearning approach (enquiry-based learning), the interdisciplinary nature of the class, the online format, and the impact the course may have had on extra-curricular activities and their future plans. The sessions were audio-recorded, transcribed verbatim, and anonymized. We analyzed the transcripts using an iterative approach, reading and re-reading the transcripts and selecting exemplar quotations, which 
are included where relevant within the quantitative results.

\section{Research Results}

\section{Quantitative Results}

Students completed a total of 106 questionnaires, 64 at the pre-course time point and 42 at the post-course time point. There was no statistically significant difference in the number of surveys completed by time point and year $(p=0.277)$. A total of 12 students participated in the qualitative arm of the study: three completed individual interviews and two focus groups were held, one with five participants, the other with four participants.

Among the significant outcomes, the questionnaires revealed that the majority of students (57.1\%) spent 1-2 hours per day on the course, with another third indicating they spent 3-4 hours per day. This is a significant time commitment for first-year students to give to an elective course. One student reported, "I got so engaged in it that I would spend a couple of hours a day on this course alone," suggesting that there was sufficient interest inherent to the course that it should garner such a significant investment of time. Only one-quarter of students had previously taken an online course. Although two- thirds of the students said that they would take an online course in the future, over three-quarters (76.2\%) said they would take this exact course again.

The majority of students reported that the various technological components of the course were easy to use. Only one-third of students consulted the technology help desk during the semester (Figure 1). While over one-third of students indicated that technological glitches hindered their learning, nearly two-thirds reported that the course increased their ability to use technology.

In terms of the PEAR tool, the wiki tool, and the discussion forums, the majority of students agreed that the instructions were clear, that these tools were easy to use, and that they were useful to their learning. That is not to say that some students did not experience technology anxiety or other challenges. One student explained:

I had a lot of frustration at some points, just because of the age we're at, we were raised with computers. I just kind of expected to walk in and get it and that everything would be there. Eventually, once we actually paid attention to what everything was supposed to do, and once I actually took the time to read all of the posts about that, then everything made so much more sense and it ended up being like a really good course. I feel like I learned a lot.

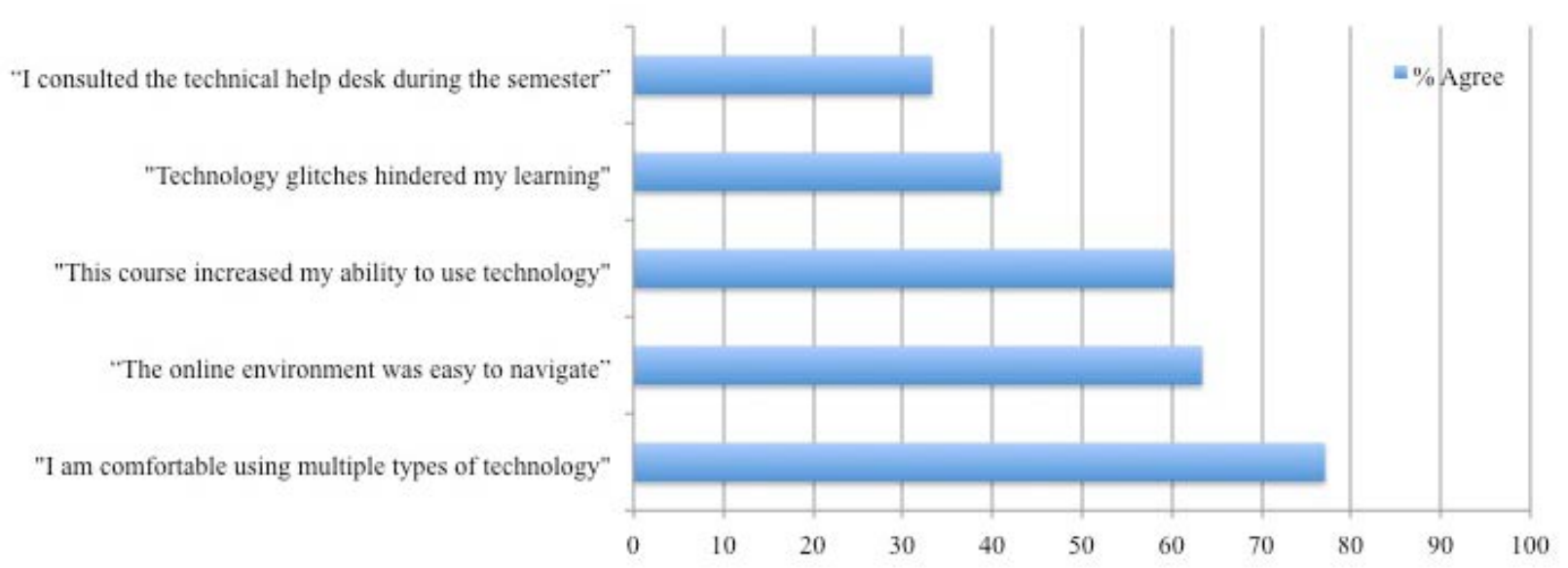

Figure 1

Student assessments of technology-related experiences (percentage of received responses) 
This student reveals student expectations that technology be readily accessible and impatience when confronted with unfamiliar or complex systems. Once students read the directions about the structure and learning technology, which had been very carefully planned in advance, it became clear and worked well. It is also significant, given EBL's goal to slow down the thinking process, that the student recognized that the way to master navigation was to read the directions and follow them, rather than to approach it randomly and impulsively.

Students reported their level of comfort with various technologies on a five-point Likert scale $(1=$ strongly disagree to $5=$ strongly agree) at the beginning and end of the semester. After taking the course students reported statistically significant increases in their comfort using the Chat tool, adding pages to a Wiki, and embedding images and videos into a Wiki page (all $p<0.01$ ). As one student summarized the technological experience, "because [the course] was online it forced me to really get to know my computer, which was a very important thing. And I also had people there to help me with my computer, which was good."

Students rated their learning skills on a fivepoint Likert scale (from $1=$ not at all to $5=$ a very considerable amount) at the beginning and end of the semester. Three statistically significant changes were found (Figure 2). Students reported a decrease in library usage $(p=0.007)$. This is not to say students stopped going to the library, especially at the beginning of the semester. One student noted that "two of us went to the Research Help in the library in the first week and [learned that] this is what we need to do and this is what I can do."

The decrease can likely be attributed to two factors. First, the very nature of an online course will reinforce electronic, Internet-based research; what is truly important is that the electronic sources that students consult become increasingly authoritative and reliable. Second, the mode of research presentations was also online and the wiki encouraged a variety of modes of presentation that moved beyond a conventional essay or classroom presentation. Thus, students encouraged each other to pursue research outside traditional library resources. For example, one student said, "I was told to use more ways of research and I was told to even try YouTube and I had never thought of that before, but after that you start using videos and stuff." In the process, many students came to see research as in-depth, engaging, enjoyable, and encouraging of intellectual engagement. Thus, while library usage, understood to be actual visits to the library building, may have decreased, attentiveness to

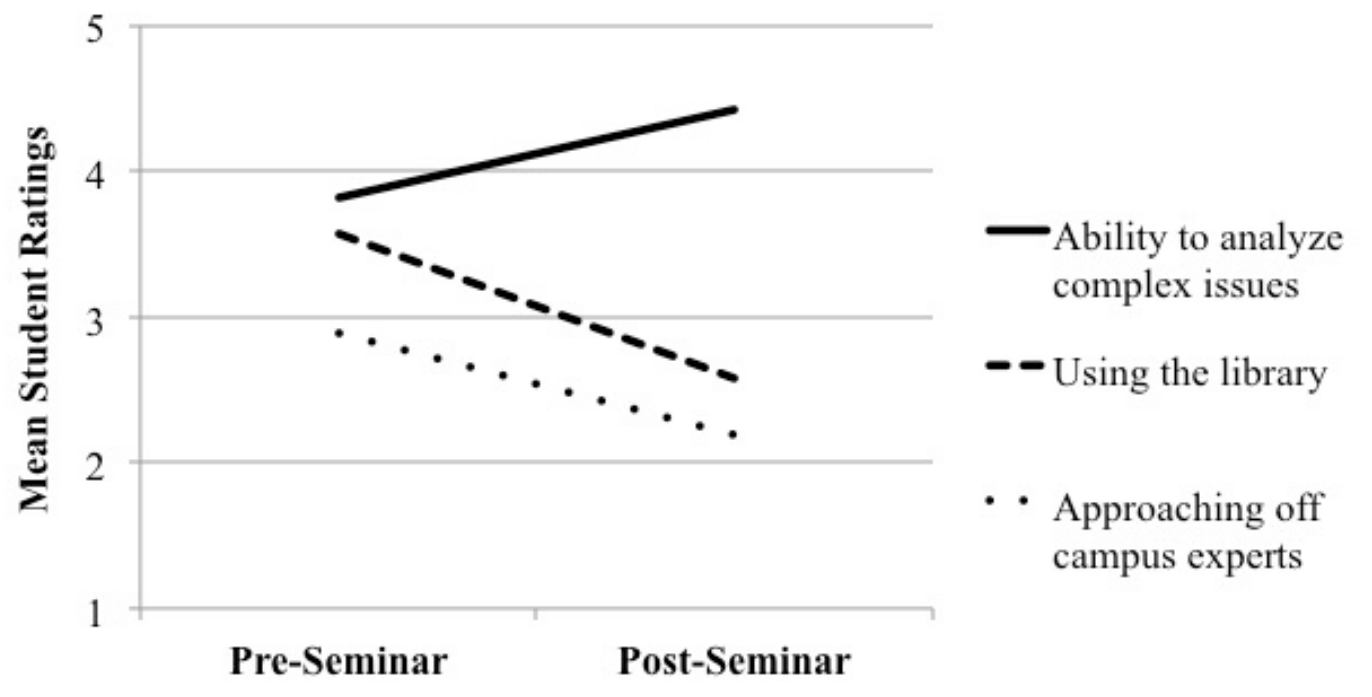

Figure 2

Changes in students' self-assessed learning skills on a scale of 1-5 
the quality and quantity of research were clearly heightened and students appreciated that their research skills would subsequently prove useful.

The questionnaires reveal a drop in students approaching off-campus experts $(p=0.045)$. There is little qualitative discussion to account for such a drop. Indeed, the anecdotal evidence of the facilitator would counter this perception. There was a high level of approaching experts who could provide specialized advice on issues. This included scientists developing innovations to alleviate hunger, officials at the IMF and the World Bank, interaction with the Executive Director of Meal Exchange, the President of Campbell's Soup, and a building contractor. In other words, there was considerable interaction with a variety of experts. The question remains, why was this not the students' perception? Did they have a different understanding of what constitutes an expert?

Finally, students reported an increase in their ability to analyze complex issues $(p=0.012)$. Indeed, "problem-solving," which came to be shorthand for the analysis of issues, was identified as an important transferable skill students would bring to further studies. This is an expected outcome of the process of EBL, which slows down the thinking process and heightens students' consciousness of critical thinking and analysis. As one respondent astutely summarized:

I think in like normal academia we just rush through those steps. So it was really interesting for the course to slow down the mental processes and really break everything down because I think we do that subconsciously but we do it really quickly. It was interesting to slow down and see the processes, see the steps that we go through [in analyzing].

Thus, the acquisition of analytical skills was one of those most explicitly understood and appreciated by the students.

The final quantitative questionnaire asked students to rate their frequency of using various types of research resources on a five-point Likert scale (from $1=$ never to $5=$ always) at both the beginning and end of the semester. The three most popular resources pre-seminar were the Internet, journal articles, and course guides. After the course, the Internet and journal articles remained the top two most frequently used resources, but government reports and statistics were the next most frequently consulted. Students reported that they used library search engines least frequently. One statistically significant change was the students reported decreased reliance on the professor $(p=0.008)$. One student noted, "if we want more content, we make more content. We have the control." Given that one of the goals of EBL is to help students become independent and autonomous learners, this is an excellent observation.

\section{Qualitative Results}

The analysis of the qualitative information focused on four major themes: 1) the EBL format, 2) critical thinking and analysis, 3) collaborative learning and teamwork, and 4) research. Students perceived the value of the EBL process and applied it in other contexts. One reported, "I was telling my roommates how to use the 'what we know, what we don't know and learning issues.' I was like, 'Guys, seriously. This course I am taking helps you break down everything." The excitement and appreciation for this mode of learning are reflected in the words of another student, "I used it to write an essay for a different class and my friends thought I was crazy because I was so happy. I was 'Look at this! Look at this outline! I am so set!' and I have never written a better essay." The EBL course also helped students develop resilience when confronted with a difficult problem. One student revealed that "I learned that sometimes you have to do stuff you don't want to do, and you don't understand how to do it, and you have to learn to work through that."

A number of students agreed that slowing down the thinking process enhanced their analysis. One reflected that "I think when you have something that's really big [and] you have to figure out what the actual problems are ... you take it slow and figure it all out." This was a skill that some students applied in other courses. "I've started just analyzing things in my other courses without even thinking about it, [and] probably think a lot more critically in my other courses." 
Students discussed how they worked as a collaborative team, and the importance of this opportunity to develop group skills. Group processing is central to developing group cohesion and collaboration. One student noted:

I thought that was one of the best things about that course, that there was the constant group processing. I remember one of my reviews was saying that they would like me to develop and provide examples of how they can improve personally, so through that they want to learn themselves and they want me to learn as well.

Others reflected on the team that developed in the semester and where it might go in the future. "We were talking about how we make a great team and how we would like to continue for organizations in the school, how we could come together in future years. That was really nice, to develop that teamwork." Another commented on future plans:

I am so excited, I just have so many things that I want to do for next year! And I know that I can handle it and it's because of this course and knowing all my strengths as a leader, or just as a team member. It's really really affected how I am going to get involved next year with the university.

Thus, the EBL experience helped students develop the skills of collaborative learning and envision themselves as members of a team in various settings, including voluntary and extracurricular activities.

Finally, in terms of research skills, one student exclaimed, "I learned so much in this course, about the content as well as research. I was terrified of researching and this helped me so much. I can go back and I can say in this case I learned this and it's really nice that you actually know that you are learning something. You actually learned it, not just memorized it." Students also developed an appreciation for, even enjoyment of, the research process. One student observed that "if you are interested [in your learning issues] and if you are passionate about it, you can spend five hours researching it and not feel like it was five hours." In EBL students are encouraged to enquire deeply into a topic rather than accept the information in the first source they encounter. This, too, was appreciated by students. "There are so many questions going inside of your head when you are doing research and you are slowly trying to just research one thing at a time and from that it leads to another question when you can just write them all down and make logical sense."

\section{Conclusion}

The experience of UNIV*1150 demonstrates how to deliver closed-loop reiterative enquiry-based learning in an online environment. Careful collaboration between the instructor and instructional designer resulted in a course informed by pedagogy, using good course design practices, and appropriately selected technologies that reinforced each step of the EBL process. Enquiry-based learning requires deep, close, and high-functioning learning communities of students. The trust that develops among a group, as a result of continuous assessment in group processing, leads to cohesive learning communities and supports student learning. This is in distinction to online courses that struggle with social loafing, disengagement, and miscommunication. Research on four cohorts of students reveals that they have developed significant critical, analytical, and presentation skills along with greater ease and fluency in using technologies. A major goal of EBL is to empower students to take control of their own learning and become more autonomous and less reliant of faculty and authority figures. Importantly, our results reveal that students were conscious of how they grew and developed as learners.

The outcomes of this course should encourage the development of other online EBL courses. With instructor and instructional designer working as an integrated team, it is possible to develop a course that implements learning technology and does not compromise, but indeed enhances, the essential elements of enquiry-based learning.

\section{References}

Anderson, T. (2008). Towards a theory of online learning. In T. Anderson (Ed.), The theory and 
practice of online learning (2nd ed.) (pp. 4574). Edmonton, AB: Athabasca University Press.

Barrows, H. S. (1986). A taxonomy of problem-based learning methods. Medical Education, 20(6) 481-486. VIEW ITEM

Bates, A. W. (2015). Teaching in a digital age: Guidelines for designing teaching and learning. Tony Bates Associated Ltd. VIEW ITEM

Bates, A. W. \& Poole, G. (2003). Effective teaching with technology in higher education: Foundations for success. San Francisco, CA: Jossey-Bass.

Blumberg, P. (2009). Maximizing learning through course alignment and experience with different types of knowledge. Innovative Higher Education, 34(2), 93-103. VIEW ITEM

Boettcher, J. V. \& Conrad, R. -M. (2004). Faculty guide for moving teaching and learning to the web (2nd ed.). Phoenix, AZ: League for Innovation in the Community College.

Chickering, A. W. \& Gamson, Z. F. (1987). Seven principles for good practice in undergraduate education. AAHE Bulletin, 39(7), 3-7. VIEW ITEM

Donnelly, R. (2004). Investigating the effectiveness of teaching 'online learning' in a problembased learning online environment. In M. Savin-Baden \& K. Wilkie (Eds.). Challenging research in problem-based learning. Maidenhead, England: Open University Press

Duch, B. J., Allen, D. E., \& White, H. B., III. (1998). Problem-based learning: Preparing students to succeed in the 21st century. Essays on Teaching Excellence, 9(5). VIEW ITEM

Fink, L. D. (2003). What is "significant learning"? University of Oklahoma. VIEW ITEM
Gokhale, A. A. (1995). Collaborative learning enhances critical thinking. Journal of Education Technology, 7(1). VIEW ITEM

Goldring, L., \& Wood, J. (2009). A guide to the facilitation of enquiry-based learning for graduate students (2nd ed.). Manchester: Centre for Excellence in Enquiry-Based Learning, The University of Manchester.

Hmelo-Silver, C. E. (2004). Problem-based learning: What and how do students learn? Educational Psychology Review, 16(3), 235-266. VIEW ITEM

Hmelo-Silver, C. E. \& DeSimone, C. (2013). Problem-based learning: An instructional model of collaborative learning. In C. E. Hmelo-Silver, C. A. Chinn, C. Chan, \& A. M. O'Donnell (Eds.). International handbook on collaborative learning. New York, NY: Taylor $\&$ Francis.

Kahn, P. \& O'Rourke, K. (2004). Guide to curriculum design: Enquiry-based learning. Heslington, York: Higher Education Academy. VIEW ITEM

Kear, K. (2010). Social presence in online learning communities. Proceedings of the $7^{\text {th }}$ International Conference on Networked Learning 2010. Aalborg, Denmark. VIEW ITEM

Kemp, S. (2011). Constructivism and problem-based learning. Singapore: Temasek Polytechnic, Learning Academy. VIEW ITEM

Kenny, R. F. (2006). Using problem-based learning in online courses: A new hope. In M. Bullen \& D. Janes (Eds.), Making the transition to elearning: Strategies and Issues. Hershey, PA: Idea Group. VIEW ITEM

Kuh, G. D. (2008). High-impact educational practices: What they are, who has access to them, and why they matter. Washington, DC: 
Association of American Colleges and Universities. VIEW ITEM

Lin, B., \& Vassar, J. A. (2009). Determinants for success in online learning communities. International Journal of Web Based Communities, 5(3), 340-350. VIEW ITEM

Murray, J., Giesbrecht, N., \& Mosonyi, S. (2013). Enquiry, engagement, and elearning: Three perspectives on a student-centred, online, enquiry-based course. Collected Essays on Learning and Teaching 6. 34-40. VIEW ITEM

Murray, J. \& Summerlee, A. (2007). The impact of problem-based learning in an interdisciplinary first-year program on student learning behaviour. Canadian Journal of Higher Education 37(3), 85-107. VIEW ITEM

Palloff, R. M. \& Pratt, K. (2005). Collaborating Online: Learning together in community. San Francisco, CA: Jossey-Bass.

Savery, J. R. \& Duffy, T. M. (2001). Problem-based learning: An instructional model and its constructivist framework (Tech. Rep. No. 1601). Bloomington, IN: Indiana University, Center for Research on Learning and Technology. VIEW ITEM

Savin-Baden, M. (2007). A practical guide to problembased learning online. New York, NY: Routledge.

Summerlee, A. \& Murray, J. (2010). The impact of enquiry-based learning on academic performance and student engagement. Canadian Journal of Higher Education, 40(2), 78-94. VIEW ITEM

Swan, K. (2002). Building learning communities in online courses: The importance of interaction. Education, Communication \& Information, 2(1), 23-49. VIEW ITEM
Vygotsky, L. S. (1978). Mind in society: The development of higher psychological processes. Cambridge, MA: Harvard University Press.

Weimer, M. (2014). Clarifying our understanding of constructivism. The Teaching Professor, 28(1), 4. Madison, WI: Magna Publications.

West, J. A. \& West, M. L. (2009). Using wikis for online collaboration: The power of the read-write web. San Francisco, CA: Jossey-Bass.

\section{Acknowledgements}

The authors wish to acknowledge the support of the University of Guelph First-Year Seminar Program, including all of the instructors and students. The authors thank Jack Mallon, Meagan Stewart, and Kelsea Martin who assisted with data entry and transcription, Dale Lackeyram who read an earlier version of this article, and the anonymous reviewers for their immensely helpful comments and valuable advice.

\section{Biographies}

Jacqueline Murray is Professor of History at the University of Guelph where she also served as Dean of Arts (2001-2006) and as Director of the First-Year Seminar Program (2011-2016). She earned a BA from the University of British Columbia, and an MA and $\mathrm{PhD}$ in Medieval Studies from the University of Toronto. Jacqueline is engaged in the Scholarship of Teaching and Learning, focusing on the impact of first-year seminars and the transformative power of enquiry-based learning. She has published articles in the Canadian Journal of Higher Education, the Canadian Journal of the Scholarship of Teaching and Learning, and Collected Essays on Learning and Teaching. Her teaching has been recognized by a number of awards including a $3 \mathrm{M}$ National Teaching Fellowship (2014). 
Nathan Lachowsky is an Assistant Professor in the School of Public Health and Social Policy at the University of Victoria. He earned a BSc and $\mathrm{PhD}$ from the University of Guelph. He was awarded a Teaching and Career Development Fellowship to design and offer an enquiry-based learning seminar in the First-Year Seminar Program. Nathan is engaged in the Scholarship of Teaching and Learning, focusing on rigorous evidence-based research on the impact of pedagogy and practice. He is an instructor of both classroom-based and distance education courses, and has a particular interest in technologyenhanced learning.

Natalie Green is the Manager of Distance Education in the office of Open Learning and Educational Support at the University of Guelph. She earned a Master's degree in Educational Technology from the University of British Columbia, a Certificate in New Media from Sheridan College, and an Honours Bachelor of Arts degree in Art History and Fine Art from the University of Guelph. Natalie leads a team of instructional designers to design and develop online undergraduate, graduate, and non-degree courses and programs and provides leadership to a broad cross-functional team responsible for the delivery of distance education offerings. 


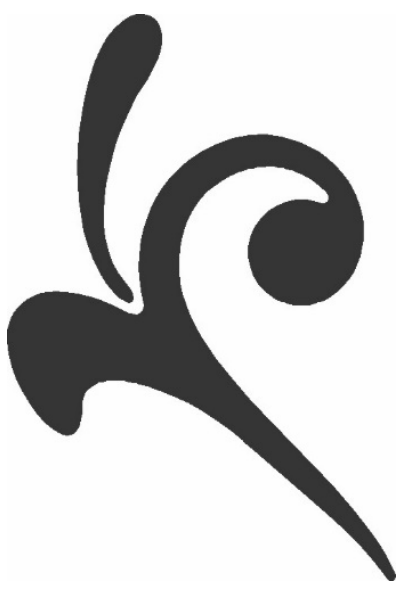

